\title{
DANÇA NA EDUCAÇÃO: A BUSCA DE ELEMENTOS NA ARTE E NA ESTÉTICA
}

\author{
LuCiana Fiamoncini*
}

\section{RESUMO}

Nesta pesquisa tivemos o intuito de desenvolver uma fundamentação teórica para a dança na educação, com base em elementos da arte e da estética. Temos como pressuposto metodológico a realização de uma pesquisa teórica baseada na hermenêutica. $\mathrm{Na}$ arte identificamos como primordiais a criatividade e a expressividade, e na estética, a sensibilidade. Acreditamos que esses elementos formam o tripé básico para o trabalho com a dança tanto na educação formal quanto na educação informal.

PALAVRAS-CHAVE: Dança - Educação - Arte - Estética.

\section{INTRODUÇÃO}

Wosso desafio ao realizar este estudo é o de traçar relações que ele possa servir (talvez como outra opção) de referencial teórico para o trabalho com a dança, seja na escola, seja em outros ambientes em que se tenha como objetivo a educação.

Temos observado, ao longo das nossas experiências, que o trabalho com a dança na educação apresenta em sua maioria uma visão instrumental dela. Dentro dessa visão, o que importa saber (quando muito) refere-se à história da dança, a seus diferentes estilos e a técnicas empregadas. Esses conteúdos sem dúvida são importantes e integrantes do ensino da dança, mas não podemos reduzir tal ensino à transmissão de um conhecimento já existente, de modo a priorizar a forma e as técnicas de movimentação, dentro de um ou outro estilo de dança. Esse reducionismo se dá, em parte, em virtude de que, durante anos, a produção científica em dança se

* Professora do Departamento de Educação Física da UFSC. 
limitou a livros de história da dança, biografias e manuais de dança, contendo explicações de termos e técnicas com demonstração de passos através de figuras. Ou seja, ao que parece, o que tem acontecido na escola com relação à dança é uma conseqüência da escassez bibliográfica (com as respectivas implicações que isso acarreta à formação de pessoas habilitadas). Alia-se a esse fato a visão instrumental e funcional, imperativa de nossa sociedade capitalista. Nos estabelecimentos escolares, predominantemente, a dança aparece sob a forma de apresentações em datas festivas, e raramente como conteúdo a ser ensinado. Além disso, quando se utiliza a dança como conteúdo, este se reduz, quase que unanimemente, ao ensino técnico estilístico e a exercícios convencionais. E para a realização destes, são requeridos aperfeiçoamentos constantes, visando ao desempenho e à funcionalidade do movimento. Não se pretende aqui negar que é preciso lidar com a aprendizagem da técnica de dança, mas isso não pode impedir a imaginação e a sensibilidade para um aguçar de todos os sentidos. Vemos a participação nas datas comemorativas como algo válido, mas não com o objetivo único de agradar aos pais, de mostrar uma escola colorida, bonita, pensando apenas numa produção final. Isso significaria deixar de lado o ensino da dança como um processo de aprendizagem.

Para entender/explicar melhor a dança como facilitadora de uma educação que priorize todas as dimensões do ser humano é que nos propomos neste trabalho a estudar elementos da arte e da estética que possam contribuir para a elaboração de uma fundamentação teórica sobre o ensino da dança. Elegemos, para tanto, os seguintes objetivos:

- desenvolver uma fundamentação teórica para a dança na educação a partir de elementos da arte e da estética;

- investigar as possibilidades da dança na educação através da arte e da estética;

- contribuir para o ensino da dança como um espaço facilitador/ estimulador de mudanças humanas e sociais.

Segundo Demo (1996), uma pesquisa teórica orienta-se para a (re)construção de teorias, quadros de referências, explicações da realidade, polêmicas e discussões pertinentes. A pesquisa deve con- 
tribuir para a produção de conhecimento, para a formação básica propedêutica, ou seja, ser base para o saber pensar e o aprender a aprender. Para esse autor, a pesquisa teórica não implica imediata intervenção na realidade, no entanto é decisiva para construir condições básicas de intervenção competente. É, portanto, condição fundamental dessa competência, determinando a qualidade da intervenção. Assim sendo, optamos pela pesquisa teórica com origem na hermenêutica.

$\mathrm{Na}$ pesquisa hermenêutica, considera-se a interpretação feita a partir de uma determinada leitura, visto que se pode extrair do mesmo texto vários sentidos. Através da interpretação das leituras que servem de referência e/ou sustentáculo para a realização deste trabalho, e na condição de pesquisador-intérprete, o que se busca são pistas, orientações e possibilidades da dança na educação. Busca-se ainda compreender o que já foi experimentado e que, certamente, incidirá na ação diária daqui em diante.

\section{ASSIM TEM SIDO A DANÇA NA ESCOLA}

Neste primeiro momento do trabalho refletimos sobre questões como a influência da indústria cultural na dança dentro da escola. Abrangemos também as festas em que a dança aparece como um produto final (não como um processo ou a importância desse) apresentado às famílias em cumprimento ao calendário institucional. Como contraponto, apontamos a perspectiva das festas rituais como um espaço importante para o convívio espontâneo, criativo e artístico, de modo a ampliar as relações sociais, no intuito de celebrar e não de cumprir um protocolo.

Abordamos a questão da supremacia da técnica em relação à expressão própria no movimento. A criatividade e a expressividade tendem a se perder diante do excesso de técnicas provocado pela busca do desempenho físico e do virtuosismo na dança. Assim, ficam à margem os pensamentos, as necessidades e os sentimentos das pessoas, o que pode ocasionar-lhes uma falta de sentido para continuar dançando. Não queremos aqui negar as técnicas de dança, como já foi dito, já que não pretendemos entrar no mérito da sua produção e forma. Queremos nos ater, porém, ao uso que se faz 
dessas técnicas, lançar um olhar crítico em relação àqueles e àquelas que ainda hoje se pautam no ensino da técnica como um fim em si mesma, pois esta é uma visão restrita da dança. Como relata Vianna (1990), existem muitos que fazem 58 piruetas ou 32 fuetés, porém faltam pessoas que dançam, que apreciam a música, que colocam intenções nos gestos, que são movidas pela emoção no momento da dança.

Acreditamos na viabilidade do ensino da técnica nas aulas de dança, porém com sentido/significado dentro do contexto, mas não o contexto da razão instrumental, e sim o da razão comunicativa (Kunz, 1994). Não podemos ser coniventes com a educação competitiva, de rendimento, de sujeição; devemos assumir o compromisso de buscar alternativas, estratégias para uma educação transformadora, emancipatória, que seja mais criativa, expressiva e sensível.

Também procuramos refletir a situação da escola diante de um ensino que visa o mercado de trabalho, mas não prepara para a construção de uma sociedade mais justa e fraterna. Entendemos o conhecimento científico e tecnológico como um meio e não como um fim. Nossa sociedade enfatiza a racionalidade, dando extrema importância para o que a ciência aponta como verdade, como real e alcançável. Porém são os sonhos, os desejos, que dão sentido às nossas vidas, pois estes nos fazem romper as barreiras do que está determinado, do que se entende como possível, instigando-nos a lutar para alcançar metas antes desacreditadas. O ser humano não é movido apenas pelo pensamento, mas também pela sensibilidade, pelo que experimenta e vive, aprendendo através de suas manifestações, do seu expressar espontâneo.

\section{REFLEXÕES TEÓRICAS SOBRE ARTE E ESTÉTICA}

No segundo momento da pesquisa, nos enveredamos pelos caminhos da arte e da estética, inicialmente buscando sua conceituação (entendendo conceito como uma aproximação do significado que se procura apreender, e não como uma verdade absoluta ou imutável). Para Langer (1980), arte é "a criação de formas simbólicas do sentimento humano". Por símbolo, entende-se todo artifício 
através do qual podemos fazer uma abstração, sendo que o símbolo refere-se ao sentimento e às formas, não se limitando apenas à esfera lógica e lingüística. Arte implica modificar (criativamente) o existente para que ele chegue a ser outra coisa. Assim, entendemos arte como um canal aberto à crítica, à espontaneidade e ao momento próprio de criação, o que resulta na obra que expressa nossos sentimentos, vivências e sonhos.

Adotamos o conceito de estética encontrado em Pombo (1995, p. 377): "a partir da sua origem grega na noção de aisthesis [a estética] aparece como domínio fundamental a ter em conta quando se trata de referir o ser humano em toda sua abrangência". Etimologicamente, o termo "estética" refere-se à sensibilidade e, portanto, à propriedade de se conhecer através do sentir pessoal/particular, proporcionando a observação do mundo de modos diferentes.

A partir dos conceitos assumidos nesta pesquisa, encontramos na arte os elementos de criação e expressão como categorias para o trabalho com a dança na educação, e, na estética, a sensibilização.

A criação se dá através de inimagináveis e incontáveis possibilidades de resoluções/combinações com diferentes materiais que resultarão na obra de arte como tal, e essas combinações dependem do envolvimento, da sensibilidade de cada artista. Para que possamos ser criativos ou para desenvolver a criatividade é necessário que o ambiente seja favorável, estimulador, ${ }^{2}$ ou que pelo menos permita nossa manifestação de algum modo. Do contrário, matam-se possibilidades de desenvolvimento da criatividade, pois é difícil ser criativo num ambiente hostilizante, que não aceita idéias novas e/ou que reprime o que é fora do comum. Mas vale lembrar que a solução de problemas do dia-a-dia envolve sempre desafios, e do mesmo modo, para a criatividade também existem percalços. A pessoa que diverge das normas da sociedade incomoda, por quebrar as estruturas, e, em razão disso, inúmeras vezes sua criatividade é bloqueada e reprimida. É necessário, no entanto, saber questionar sempre, inclusive o inquestionável, para perceber novas possibilidades, novas combinações, antes sequer cogitadas. Nesta procura, é essencial a confiança em si e em suas idéias, mas principalmente é vital que se 
tenha liberdade e coragem para enveredar por trilhas desconhecidas, desafiando muitas vezes idéias já consagradas.

A liberdade de criação em diversos momentos teve de ser conquistada, e isso é o que muitas vezes provoca maior interesse em expressar e divulgar idéias no campo artístico. O expressar criativo e crítico de um pensamento passa necessariamente pela busca da liberdade ou por espaços que se aproximem dela. Deste modo, criatividade, várias vezes, implica criticidade para a superação de obstáculos/percalços na realização de uma obra.

A expressão em arte diz respeito à manifestação de pensamentos, sensações, sentimentos ou idéias, através de um símbolo - algo criado e que constitui o propósito da arte (Langer,1980). Ou seja, a expressão da emoção, da sensibilidade, do sentimento na arte se dá não de maneira direta, mas a partir da criação simbólica, na qual se pode realizar uma abstração do sentimento que se deseja abordar.

$\mathrm{O}$ artista se expressa através de sua obra, mas não transmite um significado explícito, como acontece na linguagem conceitual. A carga expressiva contida na obra de arte indica sensações e sentimentos e não pode ser traduzida por palavras ou mesmo por outra obra na tentativa de encontrar sinônimos. Pode-se, é claro, falar ou escrever sobre as impressões que determinada obra nos causa; podese, por exemplo, criar uma dança a partir da emoção/sensação provocada por um quadro, mas isso não significa que o quadro e o símbolo artístico que o compõe transformaram-se em dança. Apenas queremos dizer que é perfeitamente válido e igualmente rico a inserção de uma obra na outra, mas não há a tentativa de uma arte explicar a outra como sucede na tradução de uma palavra de um idioma estrangeiro para outra na língua que se compreende melhor.

Importa aqui reafirmar que "o sentido expresso numa obra reside nela mesma” (Duarte Júnior, 1991, p. 45). Não é possível encontrar o sentido literal de uma obra de arte, em virtude da ambigüidade, incerteza, fantasia, riqueza de imagens, associações de palavras e tantos artifícios empregados nas mais diversas obras existentes. Seu sentido expressivo está invariavelmente atrelado à forma artística assumida.

A criação é um momento intenso de expressão que resulta no símbolo artístico. Tal expressão virá ao mundo na forma e no mo- 
mento em que a criatividade, aliada à sensibilidade do artista, considerá-la pronta. "A função expressiva da arte - e da dança vai-se resolvendo no processo de criação [...] do mesmo modo, a função expressiva só encontra sua plena realização na relação com o fruidor" (Dantas, 1999, p. 60). O que define a obra é sua forma (significante) assumida. Desse modo, uma obra tem implícitos sentimentos/idéias do artista, e quem a contempla mergulha na expressividade que esta carrega consigo. Seu sentido varia de acordo com as vivências anteriores da pessoa que a observa.

Quanto à sensibilização, esta diz respeito aos refinamentos dos nossos sentidos, sendo que eles estão frente a frente com os estímulos do mundo (sabores, cores, texturas...). Tudo o que nos chega por meio dos órgãos dos sentidos traz consigo uma impressão, ou melhor, um significado. $\mathrm{O}$ saber sensível refere-se às impressões primeiras que temos de tudo que está a nossa volta e à incorporação destas a tantas outras que já fazem parte de nossas experiências.

Sensibilidade, para Santin (1995), pode ser entendida sob dois aspectos gerais: o modo de conhecer e a vida afetiva. Inicialmente, sensibilidade seria a propriedade de ter sensações (o sentir), de experienciar, de compreender, de conhecer intuitivamente através do que é vivido. "Trata-se de um conhecimento que nos é vinculado existencialmente ao objeto 'conhecido', ou, melhor dito, sentido" (p. 36). Quanto à relação da sensibilidade com a vida afetiva, ou seja, com as emoções de modo geral, é esse o aspecto mais difundido. Ele é tido como responsável por atitudes condenáveis, desprezíveis na vida do ser racional e principalmente do cientista.

O saber sensível é a possibilidade aventada para novas formas de elaboração do conhecimento, tendo como ponto de partida a existência humana, ou seja, o vivido. A sensibilidade precisa ser retomada como um conhecimento/saber válido que represente a volta do sujeito e da subjetividade na produção do conhecimento, trazendo à tona temas que são indubitavelmente importantes, como a felicidade, a paz, a beleza. Nesse contexto, Schiller ${ }^{3}$ aponta para a reflexão sobre "a educação estética do homem”. Segundo Pombo (1995, p. 377), educação estética não significa especificamente educação artística ou teoria e crítica de arte, mas propõe fundamentar a "necessidade de um desbloqueamento das potencialidades do ser humano". 
Schiller propõe a urgência de uma educação estética voltada para um refinamento dos sentidos, para a totalidade do ser humano, visto que "todo homem individual, pode-se dizer, traz em si, quanto à disposição e destinação, um homem ideal e puro, e a grande tarefa de sua existência é concordar, em todas as suas modificações, com sua unidade inalterável" (Schiller, 1995, p. 32). Diante da perda dessa unidade, o autor acredita no caminho de restabelecimento do ideal de igualdade através da educação estética. Ao longo de suas reflexões, traz um entendimento de sensibilidade e racionalidade, sendo a sua efetiva associação responsável pela plenitude da humanidade.

A partir disso, buscamos compreender melhor o fenômeno da dança em relação às outras artes. Sabendo da dificuldade de defini-la em toda sua extensão, adotamos o entendimento de dança como a arte de expressão em movimento. E destacamos a singularidade desta em relação às outras artes em virtude de sua existência se dar através de seu criador, ou seja, na dança, artista e obra são um só.

\section{DANÇA NO CONTEXTO DA ARTE E DA ESTÉTICA}

Como terceiro momento do trabalho, procuramos relacionar com a dança e a educação os elementos que para nós se destacaram na arte e na estética. Fomentamos a dança na escola como uma perspectiva crítica à educação que promove o bloqueio da sensibilidade.

A arte, bem como a estética, tem seu valor cada vez mais incontestável na escola que visa uma educação voltada ao desenvolvimento do potencial de sentir, expressar e criar do ser humano. Arte e estética desenvolvem uma forma de inteligência diferente, de agir criativamente, de expressar-se melhor e com mais segurança, de sentir e perceber melhor o que está à volta, de estar preparado para o diverso e o imprevisível, sempre apto à mudança.

Primamos aqui pela presença ativa da arte pela sua importância no processo de formação das pessoas. Defendemos especificamente a dança, que, nos locais e momentos cujo princípio seja a educação do ser humano, constitui uma perspectiva de pessoas mais sensíveis, criativas e expressivas.

Ao envolver experiências ligadas ao desenvolvimento da sensibilidade - as quais lidam com os sentidos da visão, tato etc. -, a 
educação potencializa não somente o pensamento lógico, mas também o pensamento sensível. É essencial que se compreenda: razão e emoção estão conectadas uma à outra, e a supremacia de uma ou outra só poderá resultar na incompletude, na sectarização, no equívoco, gerando, entre tantas outras conseqüências, a infelicidade.

Destacamos, segundo Kunz (1994), a descoberta de um sabersentir pela dança, em que o corpo - como detentor de processos sensíveis e como algo que permite/provoca o sentimento de estar no mundo - consiste no saber primeiro de que nos valemos para estabelecer relações com as pessoas, com o mundo, com os outros saberes.

Nesse sentido, remetemo-nos a Duarte Júnior (2001), quando se refere à palavra saber como verbo que indica 'ter o sabor de', o que significa a integração de saberes (aprendizados) por meio de sentidos; ou seja, o saber captado/percebido pelos sentidos tem um sabor, feito um alimento que se degusta e que passa a fazer parte de nós. Esse sabor pode proporcionar o prazer de saber de si e do mundo, tendo a possibilidade de uma vida mais plena. Assim a expressão "saber-sentir" pela dança se adequa ao que estamos tentando dizer; ou seja, pela sensibilização dos sentidos, passamos a sugerir uma "alimentação saborosa" de saberes, informações, aprendizados que nos chegam das mais variadas fontes e formas, porém mais especificamente (de acordo com nosso foco de estudo) através da dança na escola. O saber sensível mostra-se, deste modo, contrário à idéia da educação como uma atividade dura, enfadonha, desprazerosa.

Para o ensino da dança, de acordo com a compreensão que temos desta como a arte de expressão do ser humano e a possibilidade de encontro consigo mesmo, acreditamos na viabilidade da improvisação. Entendemos que este seja o caminho mais recomendável para quem se propõe a ensinar a dançar, um caminho que favorece a criatividade, a experimentação, a superação dos modelos (tanto de movimento quanto de pensar, de sentir).

Improvisação na dança significa dar forma espontânea aos movimentos, realizar movimentos não treinados, ou seja, a improvisação conduz à descoberta, à criação pessoal, possível a todos (Saraiva Kunz,1994). O aluno, no momento da improvisação, tem de lidar com o não planejado, com o imprevisto, buscando resolver a tarefa que lhe for apresentada através de movimentações criati- 
vas, despindo-se das formas tradicionais e esteriotipadas (muitas delas fornecidas pela Educação Física e pelo esporte). "Neste sentido, a dança através da improvisação é um importante veículo de aprendizagem, pois proporciona a abstração dos significados que o símbolo permite, não se reduzindo a um adestramento de movimentos" (Saraiva Kunz,1994, p.168).

Aqui, o sentimento de êxito no aprendizado da dança não depende da melhor execução de movimentos técnicos, mas de realizar movimentos que deixem transparecer sensações/sentimentos, pois, no conceito da educação estética, expande-se a idéia de dar sentido à dança (Lange, 1999).

Para Saraiva Kunz (1994, p.168), no "espaço da Dança-Improvisação, o ser humano expressa-se com ou sem instrumentos e elementos alheios a ele e estabelece relações consigo mesmo e com os outros".

Nossos propósitos e a dança como um universo de possibilidades fazem que sintamos a necessidade de visualizar, entender e explicar a que dança nos referimos, até porque essa é uma indagação que ocorre freqüientemente.

Em virtude de experiências com a improvisação no projeto de extensão, acreditamos na relevância de apontar alternativas para uma educação transformadora. Através desse projeto foi possível afirmar a riqueza das aulas de improvisação não só pela observação do envolvimento e satisfação dos participantes, mas por experiência pessoal, sentida. No decorrer das aulas, vimos consolidar as perspectivas em relação a elas, ou seja, na "dança-improvisação todas as pessoas têm capacidade de ser criativas, expressando a criatividade de maneiras diferentes" (Soares et al., 1998, p. 37).

A dança-improvisação, como educação estética, pode, portanto, ser encarada como um desafio para a descoberta de movimentos interessantes, de modo a despertar a criatividade para desfechos imprevisíveis.

\section{CONSIDERAÇÕES FINAIS}

A arte se apresenta como um saber que dispõe de artifícios de resistência, como o desprezo às regras e à gramática, pois acredita que o criar inicia-se com a desconstrução. Esse ímpeto da arte pode/ 
deve ser reconhecido nas pessoas no processo educacional. Considerando que a estética reconhece o ser humano em sua completude, a educação tem muito a acertar ao propor a potencialização dos sentidos fornecendo experiências capazes de conduzir à transcendência dos problemas e das limitações da vida. A dança, uma das possíveis experiências, mostra-se como o veículo que traz a bordo os elementos da arte e da estética vistos como necessários à educação: criação, expressão e sensibilização.

Assim a dança, entendida como a arte de expressão em movimento, destaca na educação a ótica da sensibilidade, da criatividade e da expressividade, como uma nova direção que se quer dar para a razão, a ética, a cultura, e a estética - pelo saber através do sentir, da intuição, e com o objetivo de uma vida melhor e mais digna para as pessoas.

Almejamos uma educação que se afirme na sensibilidade, na vivência, no sentir com o outro e no sentir-se, de forma que a estética possa contribuir para o redimensionamento da percepção do ser humano como alternativa à racionalização e ao cientificismo, ao consumismo, à competição.

Sabemos que nem a dança nem a educação podem alcançar as mudanças necessárias para um mundo melhor, mas é preciso o compromisso de buscar a emancipação. Sob essa perspectiva, acenamos para o trabalho com a dança-improvisação.

Esse não é um pensamento isolado, solitário, tampouco é mera utopia, pois no decorrer de nossa pesquisa encontramos eco em autores que deram sustentação as nossas reflexões. Nesses autores encontramos também amparo para explicar a prática que desenvolvemos com o ensino de dança. Além disso, temos observado que o despertar para a arte, para a sensibilidade, tem finalidade educacional na medida em que pretende desenvolver com o aluno a autonomia, a crítica, a ética.

Ou seja, a arte consiste no alargamento das potencialidades e capacidades humanas. Ela "é potenciadora de relações, que podem apontar para as mais inesperadas descontextualizações" (Pombo,1995, p. 388). Entende-se que "a arte não pode mudar o mundo, mas pode contribuir para a mudança da consciência e impulsos dos homens e das mulheres, que poderiam mudar o mundo"' (Marcuse, citado por Pombo, 1995, p. 388). 


\title{
Dance in Education: the Search for Elements in Art and in Aesthetics
}

\begin{abstract}
In this research work we aimed at developoing a theoretical basis for dance in education. Thus, we searched for elements in Art and in Aesthetics that could contribute to this aim. Therefore, in Art we identified creativity and expressiveness as important elements; and in Aesthetics, sensitivity came out as an important element. We believe these elements form the basic tripod for the work with dance in formal as well as in informal education. The main aim of this study is to develop a theoretical basis for dance in education with elements taken from Art and Aesthetics. The methodological approach chosen for this study was a theoretical research based on hermeneutics. The reflections developed here are by no means final; however, we believe this research work brings its contribution to all who are interested in this field and it also shows the way to other possible studies in the area.
\end{abstract}

KEY WORDS: Dance - Education - Art - Aesthetics.

\section{Danza en la Educación: la Búsqueda de Elementos en el Arte y la Estética}

\section{RESUMEN}

En esta investigación tuvimos el propósito de desarrollar una fundamentación teórica para la danza en la educación. De este modo, buscamos en el arte y en la estética elementos que pudieran contribuir para este hecho. Entonces, en el arte identificamos como primordiales la creatividad y la expresividad, y en la estética, la sensibilidad. Elementos que creemos formar el trípode básico para el trabajo con la danza tanto en la educación formal como en la educación informal. Este estudio tiene como objetivo principal desarrollar una fundamentación teórica para la danza en la educación a partir de elementos del arte y de la estética. Tiene como suposición metodológicas la realización de una investigación teórica con base en la hermenéutica. Las reflexiones aquí realizadas no están de ningún modo agotadas, pero creemos que esta investigación trae su contribución para los que se interesen por el tema y también muestra caminos para otros estudios en el área en cuestión.

PALABRAS CLAVES: Danza - Educación - Arte - Estética.

\section{NOTAS}

1 Segundo Kunz (1994, p.31), a emancipação refere-se ao "processo de libertar o jovem das condições que limitam o uso da razão crítica e com isso todo seu agir social, cultural e esportivo, que se desenvolve pela educação".

2

É curioso o que cada pessoa atribui como situação ideal para o surgimento de idéias criativas. "Os relatos sobre as condições que mais favoreciam a produção de sujeitos altamente criativos mostram a grande variabilidade de ambientes estimuladores. Agatha Christie, por exemplo, dizia ficar mais inspirada para seus 
romances policiais relaxando-se em uma banheira com água morna e comendo maçãs. O poeta Hart Crane se inspirava ouvindo músicas de jazz. Schiller enchia sua mesa de maçãs podres e Mozart fazia ginástica. A posição corporal ideal para a inspiração de Kant era deitado na cama e enrolado nos lençóis, de uma maneira inventada por ele" (Wechsler, 1992, p. 29).

Friedrich Von Schiller (1759 - 1805), considerado um grande poeta e dramaturgo alemão, alcançou a expressão maior de seu trabalho na filosofia. Publicou obras sobre suas posições estéticas, dentre as quais se destacou A educação estética do homem, obra que adquire incontestável relevância.

\section{REFERÊNCIAS}

DANTAS, Mônica. Dança: o enigma do movimento. Porto Alegre: Ed. Universidade UFRGS, 1999.

DEMO, Pedro. Pesquisa e construção de conhecimento: metodologia científica no caminho de Habermas. Rio de janeiro: Tempo Brasileiro, 1996.

DUARTE JÚNIOR, João F. Por que arte-educação? Campinas: Papirus, 1991.

. O sentido dos sentidos: a educação do sensível. Curitiba: Criar Edições, 2001.

KUNZ, Eleonor. Transformação didático-pedagógica do esporte. Ijuí: UNIJUÍ, 1994.

. O movimento humano como tema. Kinein, v. 1, n.1, 2000.

LANGE, Helgard. Gymnastik und tanz in kontext ästhethischer erziehung. In: Neues Taschenbuch des Sportunterrichts. Didaktische Konzepte und Unterrichtsprxis. Band 2. 1999.

LANGER, Susanne. Sentimento e forma. São Paulo: Perspectiva, 1980. 
POMBO, Maria de Fátima T. Fenomenologia e Educação: a sedução da experiência estética. 1995. Tese (Doutoramento) Universidade de Aveiro, Portugal, 1995.

SANTIN, Silvino. Educação Física: Ética. Estética. Saúde. Porto Alegre: EST, 1995.

SARAIVA KUNZ, Maria do Carmo. Ensinando dança através da improvisação. Motrivivência, v. 5/6/7, p.166-169, dez. 1994.

SCHILLER, Friedrich. A educação estética do homem. São Paulo: Iluminuras, 1995.

SOARES et al. Improvisação e dança: conteúdos para a dança na Educação Física. Florianópolis: Imprensa Universitária - UFSC, 1998. VIANNA, Klauss. A dança. São Paulo: Siciliano, 1990.

WECHSLER, Solange M. Criatividade: descobrindo e encorajando. Campinas: Editorial Psy, 1993.

Recebido: maio de 2003 Aprovado: junho de 2003

Endereço para correspondência Luciana Fiamoncini Rua Servidão Wenceslau Martinho Vieira, $n^{\circ}$ 67, Bloco B, Ap. 105 Córrego Grande Florianópolis-SC Cep: 88037-916 